\title{
Evidence for survival in a Middle Jurassic plesiosaur with a humeral pathology: What can we infer of plesiosaur behaviour?
}

\author{
Bruce M. Rothschild, Neil D.L. Clark, and Clare M. Clark
}

\begin{abstract}
Studying bone pathology frequently provides insights into an animal's life, not only in terms of aetiology, but also how resulting limitations affected its behaviour and giving insight into potential survival strategies. A pectoral girdle of the plesiosaur, Cryptoclidus eurymerus, with the left forelimb damaged provides an opportunity to study posttrauma survival in the Middle Jurassic. Landmark data and macroscopic examination of the limb and associated scapulocoracoid are used to show that the damage was the result of an injury and not due to developmental pathology. Loss of the proximal humeral surface was associated with filigree modelling and periosteal reaction, which would have resulted in disruption of the adjacent scapulocoracoid surface rendering it functionally ineffective. This would have precluded its use in a power stroke or in providing directional locomotion. Healing of the pathology shows that it was possible for the plesiosaur not only to survive, but somehow to compensate for the loss of its limb. It is likely to have either corrected using hind-limb propulsion with the forelimbs compromised, or that the hindlimbs took a more active role in propulsion. The pectoral girdle of this specimen is smaller than would be expected for an adult $C$. eurymerus and the bones are thinner, indicating that the diet of the animal may have been restricted. The existence of healed tooth impacts on the dorsal aspect of the humerus suggests that the exostosis at the joint resulted from a pliosauroid or large crocodilian attack on the left flipper.
\end{abstract}

Bruce M. Rothschild. The Carnegie Museum, 4400 Forbes Ave, Pittsburgh, Pennsylvania 15232 and West Virginia University School of Medicine, 1 Medical Center Drive, P.O. Box 9100, Morgantown, WV 265069600.spondylair@gmail.com

Neil D.L. Clark. The Hunterian, University of Glasgow, Glasgow G12 8QQ, Scotland, UK. neil.clark@glasgow.ac.uk

Clare M. Clark. New Lister Building, Glasgow Royal Infirmary, 10-16 Alexandra Parade, Glasgow, 2ER, Scotland, UK. c.clark.1@research.gla.ac.uk

Rothschild, Bruce M., Clark, Neil D.L., and Clark, Clare M. 2018. Evidence for survival in a Middle Jurassic plesiosaur with a humeral pathology: What can we infer of plesiosaur behaviour? Palaeontologia Electronica 21.1.13A 1-11. https://doi.org/10.26879/719 palaeo-electronica.org/content/2018/2182-plesiosaur-humeral-pathology 
Keywords: pathology; plesiosaur; humerus; pectoral girdle; Middle Jurassic; Cryptoclidus

\section{*INTRODUCTION}

A functionally "three-limbed" plesiosaur provides insight to swimming behavior in a Callovian (Middle Jurassic) plesiosaur. Loss of limb use was at one time thought to severely compromise land animals to a point where extended survival would be impossible. However, three-legged deer and dogs have been observed to survive for extended periods and some (e.g., caught in a snare) will even sacrifice a limb in order to survive (Douglas, 1965; McTaggart Cowan, 1946; Rowley-Conwy, 1990). Much less is known about limb-loss survival in the marine habitat. Bite marks can often be found on the limb bones of marine and terrestrial reptiles, but it is often difficult to tell whether the bite marks are pre- or post-mortem unless there is evidence of bone regrowth where the damage has occurred, showing the injury has had time to at least partially heal (Einarsson et al., 2010; Hone and Watabe, 2010; Karl, 2012; DePalma et al., 2013; Araújo et al., 2015a).

In the case of specimen GLAHM V1799, however, it is possible to see clear evidence of bone regrowth showing that the animal survived for some time after injury and loss of function in the left anterior limb (Figure 1). Loss of use of a limb does not require its actual loss, only that it be rendered non-functional. This can result from neurologic damage such as a cerebrovascular incident (stroke), or from being rendered anatomically nonfunctional (e.g., arthritis, or injury). Limb use is dependent upon muscle function but tetrapod muscles only work when there is a fulcrum, the diarthrodial joint at which movement occurs. Metaphyseal loss deprives the joint of a fulcrum and the result is a flail joint, depriving related muscles of the ability to exert power function across the joint. The plesiosaur survived the trauma long enough for substantial bone regrowth indicating that it was able to overcome the loss of use of its anterior forelimb. Studying this example with such a mechanically non-functional forelimb affords the opportunity to evaluate the various hypotheses on plesiosaur propulsion considering its survival posttrauma.

\section{MATERIALS, METHODS, AND ACRONYMS}

Macroscopic examination was performed on a Callovian (Middle Jurassic) plesiosaur Cryptoclidus eurymerus scapulocoracoid and left humerus (GLAHM V1799) collected by Alfred Leeds from 'Pit 13' (Peterborough, England, UK). The bones were identified as belonging to Cryptoclidus eurymerus, on the basis of the expanded distal portion of the humerus and the shape of the scapulocoracoids (Andrews, 1913; Brown, 1981, figure 15). This specimen is slightly different from other specimens of $C$. eurymerus, and was previously recorded as Apractocleidus teretipes by Smellie (1916). Apractocleidus teretipes was synonymized with C. eurymerus by Brown 1981 on the basis that the bones of the type specimen of $A$. teretipes (GLAHM V1091) represented an 'old adult' of $C$. eurymerus. The bones of the 'old adult' pectoral girdles are fused along sutures and are generally thinner than 'younger' specimens (Brown, 1981). The specimens identified by the above criteria as 'old adult'; 'adult'; and 'juvenile' were compared with GLAHM V1799 using the correlation principal component analysis in PAST software (Hammer et al., 2001). The glenoid angles and the inter-glenoid and inter-posterolateral process distances were used in this comparison.

Distances between identical landmark structures and the sizes of the pectoral vacuities on the left and right sides of the scapulocoracoid complex of GLAHM V1799 were measured to determine if the damaged limb joint resulted in a developmental bias (Figure 2). The angles of the various bone sutures of the glenoid area were averaged between the left and right sides where both sides existed. The interglenoid (i.g.) and inter-posterolateral process (i.p.l.) distances were also measured and compared with other pectoral girdle specimens of Cryptoclidus eurymerus. Individual landmarks were selected for both the left and right sides of the pectoral girdle. Landmarks 1 (= landmark 13 of Araújo et al., 2015b) and 2 are on the anterior-most part of the posterior coracoid process with point 3 on the midline of the coracoids between these two points; landmarks 4 (= landmark 1 of Araújo et al., $2015 \mathrm{~b}), 5,7$, and 8 are on the posterior and anterior of the glenoid articulation, respectively; landmark 6 is at the intersection of lines between these points along the midline and on the straight line 

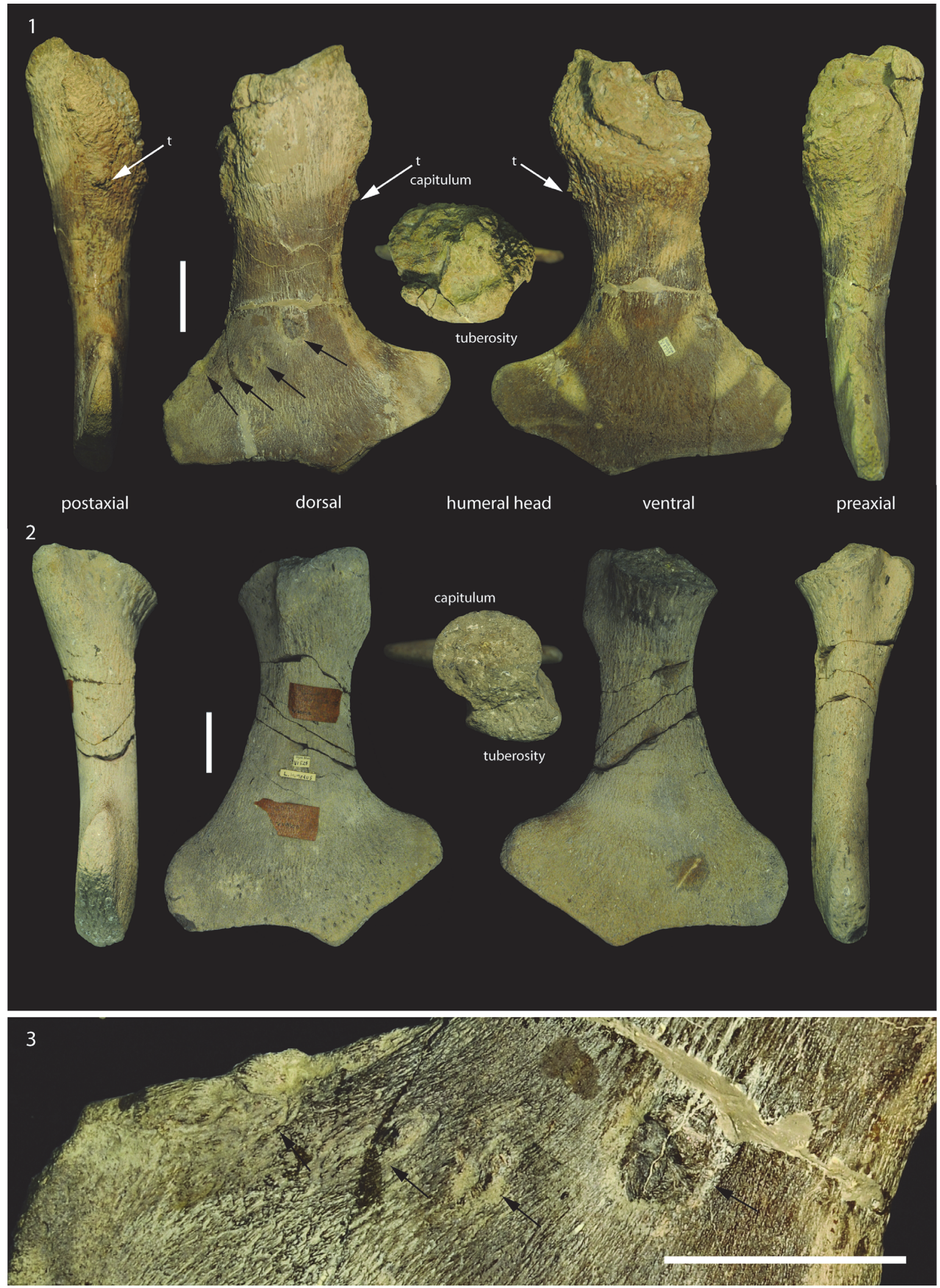

FIGURE 1. 1. Multiple views of Cryptoclidus eurymerus GLAHM V1799 left humerus (Top row) and; 2 . normal humerus (GLAHM V1828) for comparison; 3. close up of the humerus showing tooth impacts (GLAHM V1799). White arrows indicate tubercle (t); black arrows indicate bite marks. Measurement bar is $5 \mathrm{~cm}$. 
Rothschild, Clark, \& Clark: Plesiosaur humeral pathology

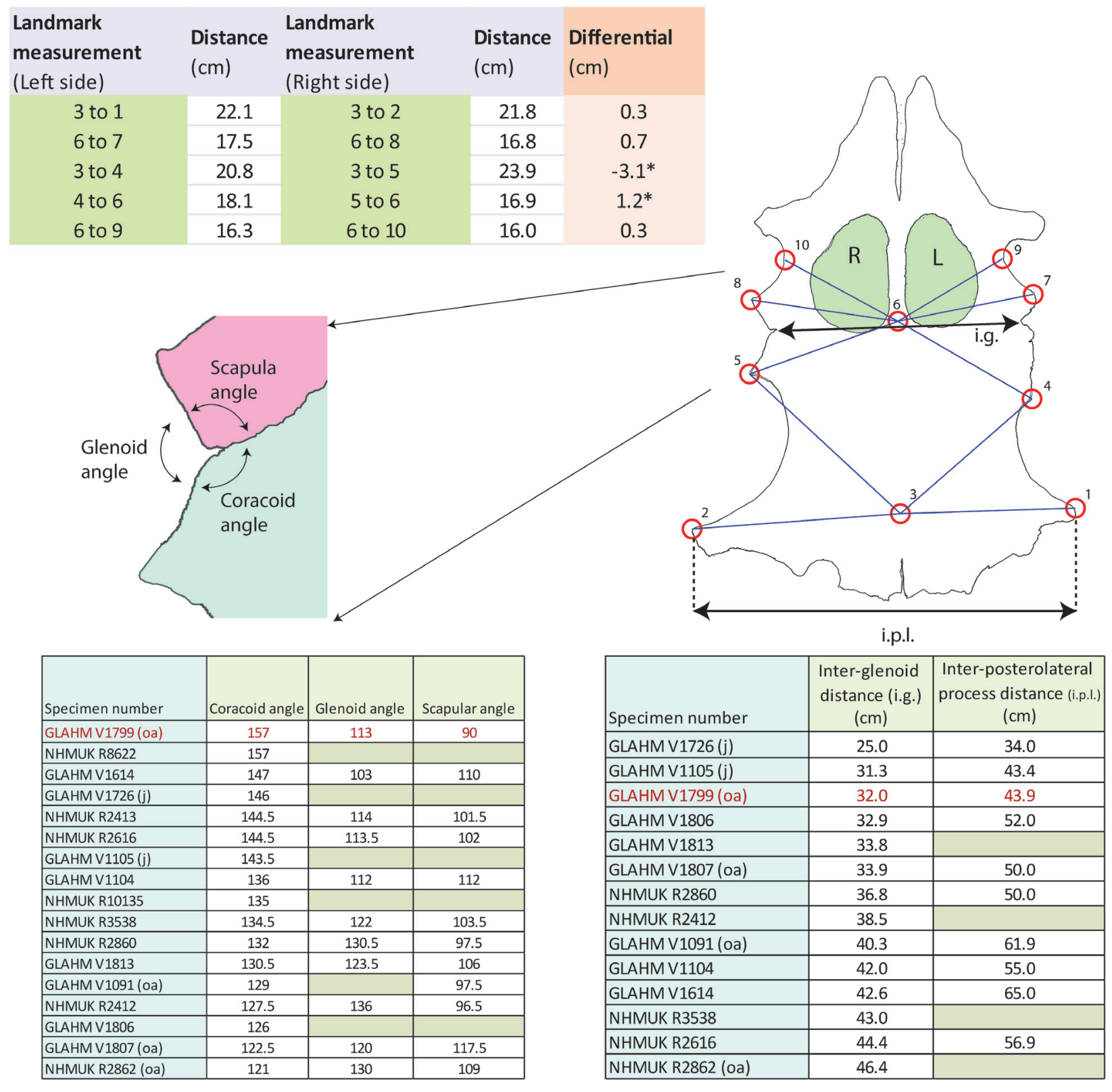

FIGURE 2. Table of pectoral girdle measurements and schematic of measurement sites. Juveniles (j) were recognized by the lack of prominent posterolateral processes and a curved posterior margin of the coracoids; (oa) denotes 'old adult' specimens where the scapulocoracoids are fused. * Difference in humeral fossa size extended by injury resulted in observed measurement variation. The mean of the angular measurements for the glenoid, coracoids, and scapula were used here (left and right measurements are included in the appendix).

between the intersections of the coracoid and scapula at the glenoid articulation (approximately equivalent of landmark 7 of Araújo et al., 2015b); and landmarks 9 and 10 are on the closest point between the left and right scapula below the scapular process (see Figure 2). These landmarks were chosen and measured by CC in 1996 as part of an undergraduate research project on the pectoral girdle of Cryptoclidus. This specimen (GLAHM
V1799) and comparative material (GLAHM V1091 GLAHM V1104, GLAHM V1105, GLAHM V1614, GLAHM V1726, GLAHM V1806, GLAHM V1807, GLAHM V1813, NHMUK R2412, NHMUK R2413, NHMUK R2616, NHMUK R2860, NHMUK R2862, NHMUK R3538, NHMUK R8622, NHMUK R10135) used in this study are held in the collections of The Hunterian (GLAHM) at the University of Glasgow, Scotland, UK, and the Natural History 
Museum (NHMUK) in London, UK. Although there is no associated right humerus, there is a right humerus that matches the length as well as the shape of the ulnar and radial articulations that may originally have belonged to the GLAHM V1799 pectoral girdle (GLAHM V1827). The paddle bones also appear to be absent from GLAHM V1799.

\section{RESULTS}

The proximal humeral metaphysis of GLAHM V1799 is missing, with residual new bone formation, filigree surface modification, and draining sinuses (Figure 1). The coracoids, scapulae, and clavicles are fused, but the suture is still visible, and the posterior edge of the coracoids is thin and ragged, suggesting that GLAHM V1799 represents an aged adult specimen (Andrews, 1895, 1913). It is thought that many of the differences in size and angles between bones in the glenoid area may be attributed to an injury sustained when the animal was younger, as the measurements are more like those of other juvenile specimens of Cryptoclidus (Figure 2). The right coracoid angle of GLAHM V1799 is unusually large $\left(157^{\circ}\right)$, and other specimens appear to show a decrease in this angle (from $146^{\circ}$ to $121^{\circ}$ ), associated with co-ossification of the pectoral girdle and thinning of the bone (Figure 2). Ontological fusion of independent bones or sutures has in the past been considered as a sign of maturity, but Hershkovitz et al. (1997) and Bailleul et al. (2016) documented that such fusion alone is not a valid measure of aging/adult status. However, the fusion in association with the thinning of the coracoids, a low coracoid angle (except in GLAHM V1799), and the ragged posterior margin all suggest an aged animal. This could also be seen in the principal component analysis plot where the specimen GLAHM V1799 plotted in a similar region to the specimens identified as 'juvenile' pectoral girdles of Cryptoclidus (Figure 3). The measurements between landmarks and the angles between the bones of the anterior pectoral girdle (Figure 2) show a slight difference between the left and right sides of the pectoral girdle in specimen GLAHM V1799 (Figure 2) as a result of the pathology. The larger differences between landmarks 4 and 5 with 3 and 6 may be due to the difficulty in finding a precise homologous landmark on the lefthand side for 5 due to the damage inflicted by the pathology (Figure 2). The articular surface of the scapulocoracoid component is eroded with reactive new bone formation (Figure 4). The two elements no longer form an intact shoulder joint. There is an unusual bony growth (exostosis) on the

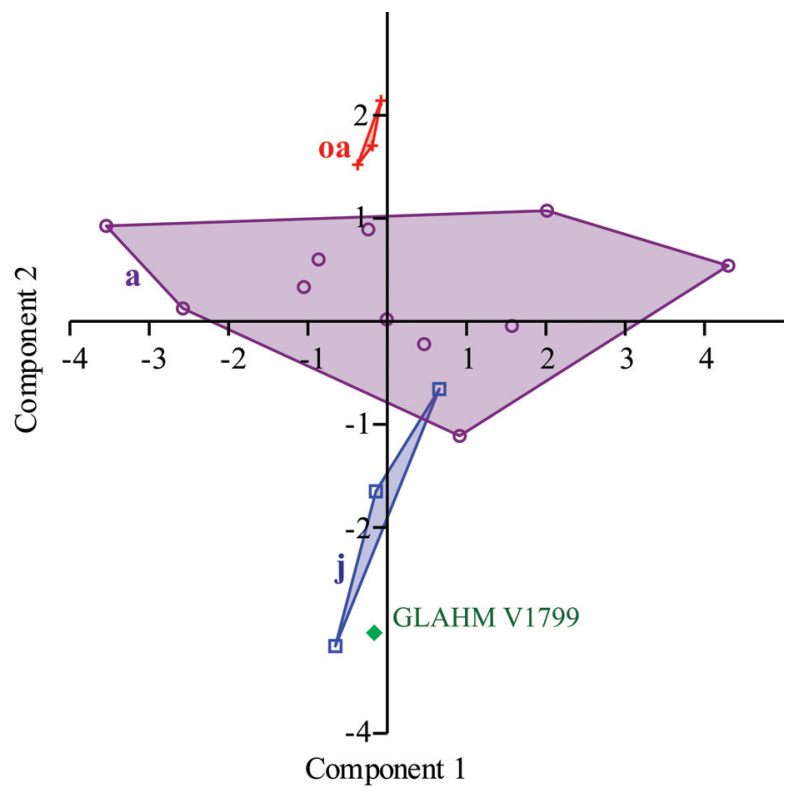

FIGURE 3. Results of the correlation principal component analysis using PAST ver. 2.17c (Hammer et al. 2001) showing that the juveniles generally morph from a larger coracoid angle towards a smaller angle in older adults (older adult (oa) $n=4$ (red); adult (a) $n=11$ (purple); juvenile (j) $n=3$ (blue); and GLAHM V1799 plotted separately (green)).

postaxial edge of the humerus. This tubercle, shown by the white arrow (Figure 1), identifies the damaged coracobrachialis insertion. Black arrows identify tooth impacts. A larger indentation on the dorsal view of GLAHM V1799 has a round $1.8 \mathrm{~cm}$ diameter tooth-shape suggesting a pliosauroid or large crocodilian attack (Figure 1).

\section{DISCUSSION}

Collapse of the proximal portion of the humerus could be attributed to avascular necrosis related to vascular compromise, infection or fracture with resorption, or failure of preservation (taphonomic) of the more proximal portion (Rothschild and Martin, 2006). Erosions of the glenoid fossa are unlikely to be taphonomic, as the bone growth is typical of an inflammatory or infectious articular process (Rothschild and Martin, 2006). The infectious nature of the pathology can be shown by the filigree new bone formation on the humeral surface and draining sinuses. If the tooth impacts of the distal shaft were associated with an impact in the humeral joint (as the evidence from the exostosis suggests), the predator would have had a tooth-row width of about $15 \mathrm{~cm}$ with teeth of up to $2 \mathrm{~cm}$ diameter. The line of the tooth impacts suggests the attack likely came from the left and 


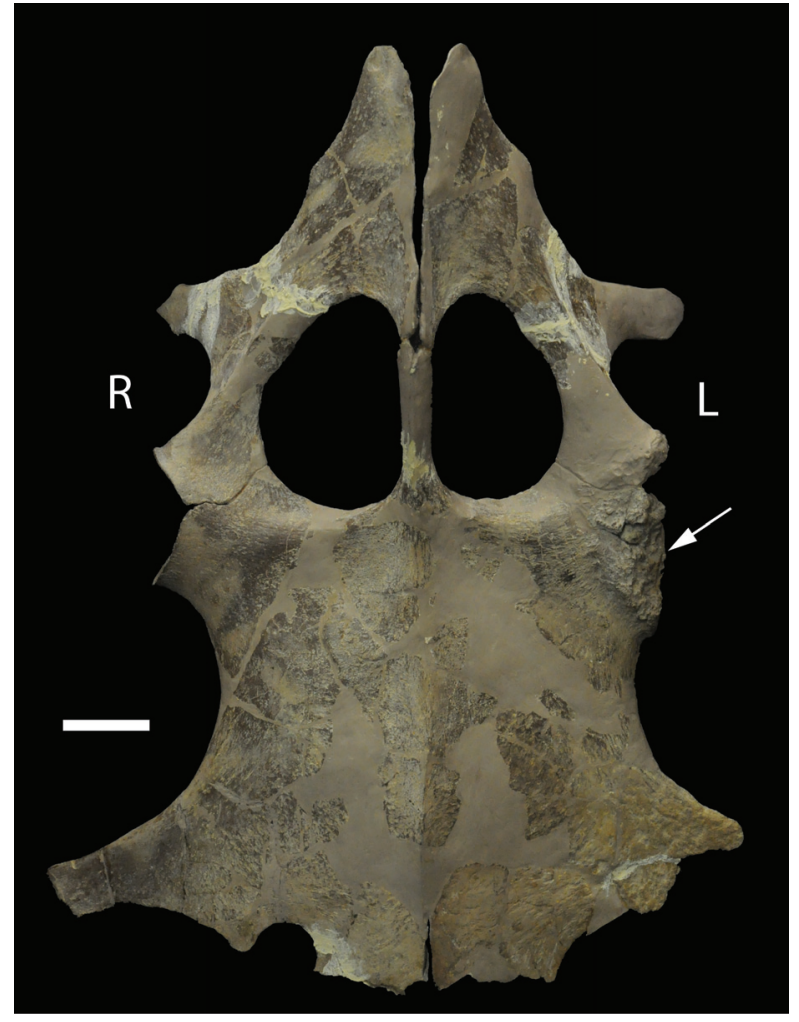

FIGURE 4. Ventral view of pectoral girdle of Cryptoclidus eurymerus GLAHM V1799. Measurement bar is 5 $\mathrm{cm}$. Arrow indicates left side glenoid fossa pathology.

behind or the front (Figure 5). The size of the bite mark and the tooth-shape suggests that the predator was probably a pliosaur, possibly Peloneustes (a small pliosaur from the same horizon (Peterborough Member of the Oxford Clay Formation) as Cryptoclidus eurymerus from Peterborough), although an as yet unknown large crocodilian with a broad jaw attacking this individual is also possible. The small size of Peloneustes ( $3 \mathrm{~m}$ ) may have made it easier for the Cryptoclidus prey (GLAHM V1799) to escape predation, despite being compromised from the injury. If it was a frontal attack, then it is possible that the plesiosaur was able to inflict injury on its attacker as well.

The thinness of the humerus (Figure 1) suggests disuse atrophy as a result of the pathology, as frequently occurs in limbs that are no longer functional (Stern, 1936). The amount of bone healing in mammals would take at least two weeks and likely, several months in reptiles (Tully, 2002; Rothschild et al., 2012; de Boer et al., 2015). The Cryptoclidus specimen (GLAHM V1799) clearly survived the attack from the predator as healing has taken place, resulting in the exostosis.

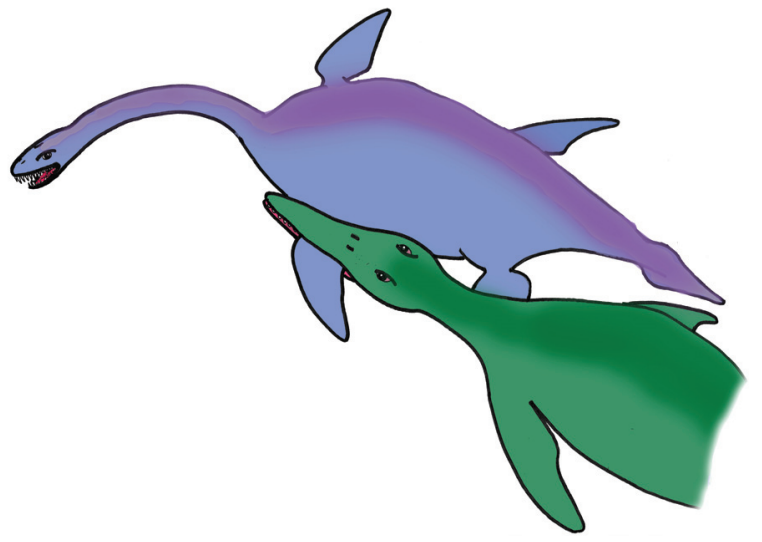

FIGURE 5. Cartoon of direction of attack on Cryptoclidus eurymerus specimen GLAHM V1799.

Collapse of the articular surface produced a flail joint, with no fulcrum for muscle action. Figure 6 offers an alternative consideration. Had the joint capsule contracted, the movement of the humerus would have been blocked by the exostosis, rendering the joint effectively immobile in the short-term. The extensive loss of articular surface, however, suggests that the bones were not in direct contact, but flailed without control. Plesiosaur forelimb paddles have only one movable joint, that between the shoulder girdle and the humerus (Liu et al., 2015), so its function is critical to use of that $\operatorname{limb}$. As to the muscles affected by the injury, function of the supracoracoideus, clavodeltoideus, and coracobrachialis were likely impaired, but the major muscle function impairment was that of the triceps and latissimus dorsi (Figure 7). The triceps attachment appears to have been avulsed. That suggests that locomotion by this plesiosaur (that clearly survived the initial infectious process) was likely impaired at least in the short term until there was a re-adaptation of the limb function to partially compensate for the temporary loss of functionality. But, how important was the front paddle to directional locomotion?

Multiple authors (Godfrey, 1984; LinghamSoliar, 2000; Liu et al., 2015; Smith, 2013) suggested that plesiosaur propulsion was dependent on the forelimbs providing the power strokes (as confirmed by modeling), with hindlimbs providing directionality. This is analogous to that of penguins (Clark and Bemis, 1979; Liu et al., 2015), sea turtles (Gaillard et al., 2003; Liu et al., 2015; Walker, 1971), and sea lions (English, 1976; Liu et al., 2015). Halstead (1989) suggested that the plesiosaur body morphotype resembles that of turtles, noting the disparate size of fore and hind limbs. Penguin and sea turtle forelimbs are hydrofoils 


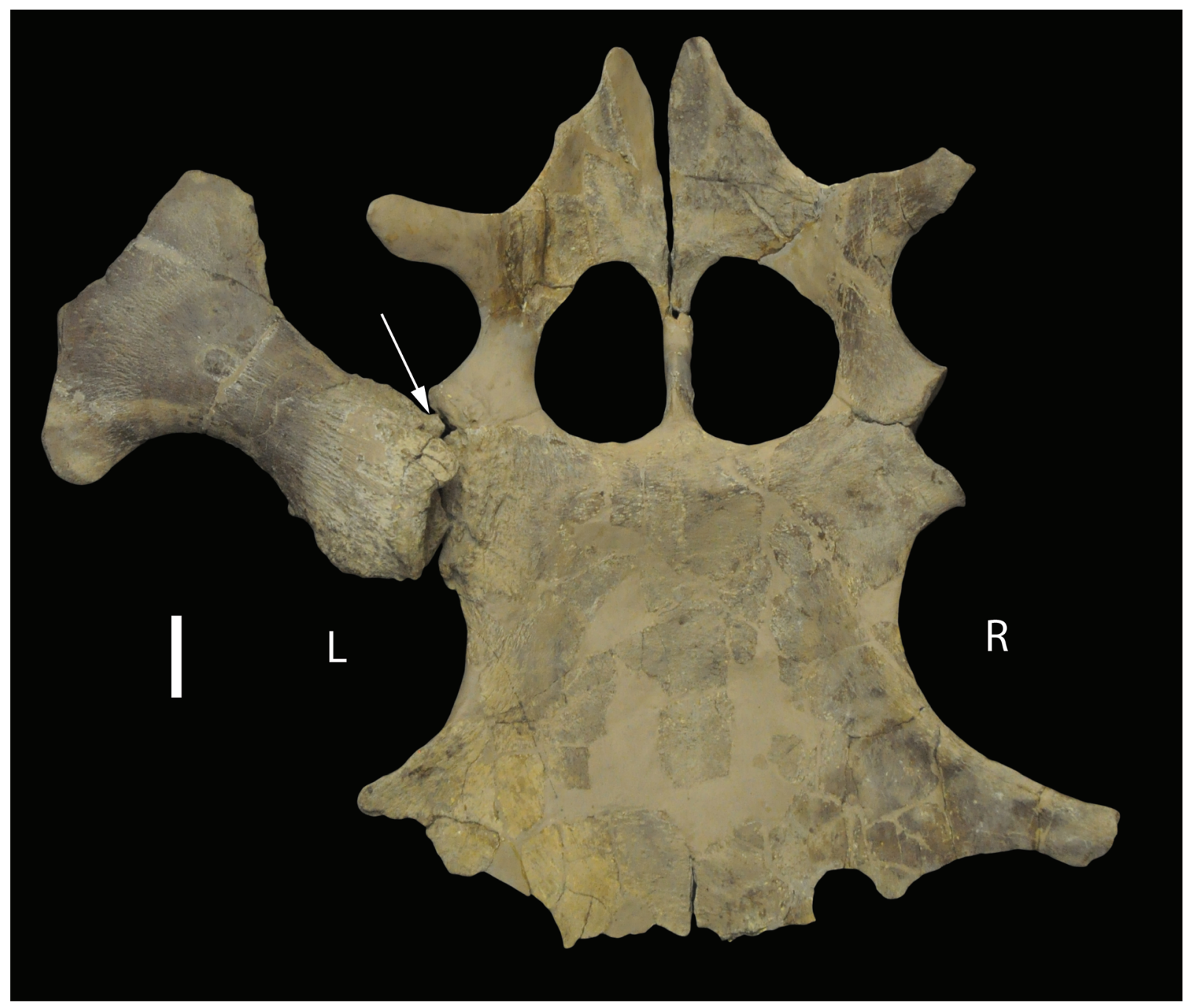

FIGURE 6. Dorsal view of left humerus and plastron, articulated as if the joint capsule had contracted. Measurement bar is $5 \mathrm{~cm}$. Exostosis (arrow) would prevent joint movement.

(Conybeare, 1824; Clark and Bemis, 1979; Riess and Frey, 1991; Carpenter et al., 2010) and are used synchronously to provide propulsion, providing a potential analogy for plesiosaur locomotion. Trackways of sea lions (English, 1976) and the sauropterygian nothosaurs document forelimb propulsion (Zhang et al., 2014). Zhang et al. (2014) on the basis of trace fossils, further suggested that the forelimb propulsion was mostly synchronous for nothosaurs and likely the same in plesiosaurs. Carpenter et al. (2010) alternatively suggested that propulsion was synchronous or near-synchronous between fore and hind limbs. Tarlo (1957) alternatively suggested hindlimb propulsion, while Long et al. (2006) modeled four limb propulsion. Long et al. (2006) noted that the latter would have a substantial and likely prohibitive metabolic cost, being used only when a burst of speed was necessary. For cruising, propulsion using the forelimbs only was more efficient. The limb-driven pattern in plesiosaurs is contrary to the oscillatory tail propulsion utilized by most diapsid marine reptiles (Massare, 1988). Halstead (1969) suggested that specialization of limbs in elasmosaurs was for speed, while those of pliosaurs, was for power. Robinson (1975) suggested that pliosaur's hindlimbs were larger than forelimbs, with forelimbs controlling yaw.

It seems unlikely that this injured plesiosaur swam in circles and hence we would have to conclude that either hindlimb function could at least to some extent correct for one-sided paddling, or hindlimb propulsion was predominant in healthy animals or facultatively available when forelimb propulsion was compromised.

Elasmosaurs and plesiosaurs, such as Cryptoclidus, were built for speed associated with rapid 

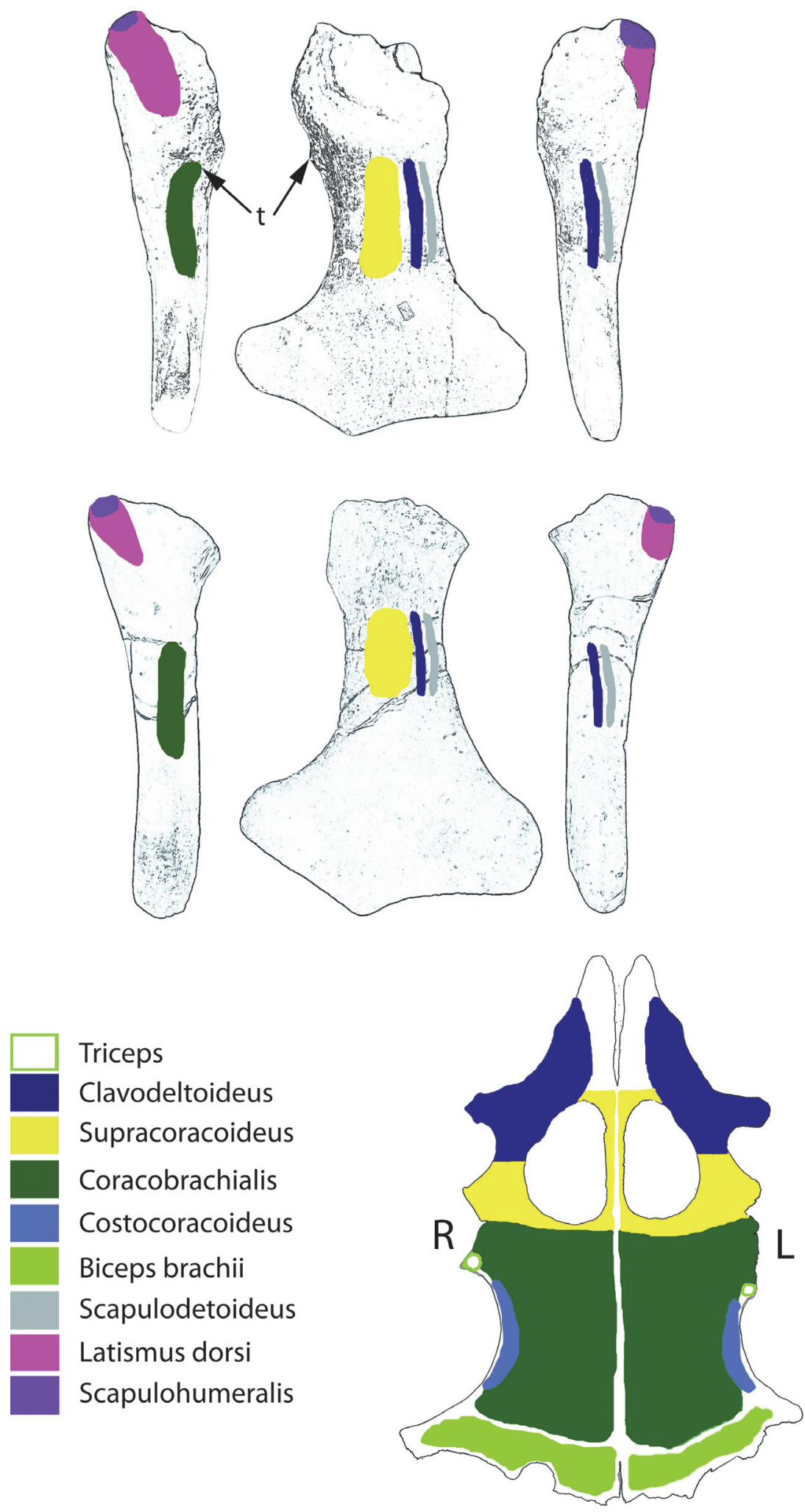

FIGURE 7. Plesiosaur muscle attachments to humerus and scapulocoracoid (Based on Araújo and Correia, 2015). Postaxial, ventral, and preaxial views of the affected left humerus GLAHM V1799 (top row) and the same of a healthy humerus (GLAHM V1828), as well as the ventral view of the pectoral girdle of GLAHM V1799 (bottom). 
changes in direction to follow prey. A plesiosaur with this pathology would likely have had difficulty keeping up with its prey. It may have had to restrict its diet to easier prey - perhaps more crustaceans, than a fuller diet of fish, crustaceans and belemnites (Chatterjee and Small, 1989; Martill et al., 1994; Maisch and Rücklin, 2000; Araújo and Polcyn, 2013). This may have led to its diminutive size and retarded development when compared to other examples of this species. The trophic structure of the Peterborough Member of the Oxford Clay Formation suggests that the benthic environment was not anoxic and contained an abundance of shallow infauna including annelids, bivalves, gastropods, and crustacea (Martill et al., 1994), although the nektonic fauna was more abundant (Hudson and Martill, 1994). If the specimen GLAHM V1799 had difficulty feeding on the nektonic prey fauna of cephalopods and fishes, it may have found it easier to survive on the benthic fauna and the occasional carcass.

There is circumstantial evidence that plesiosaurs were viviparous, and it is therefore possible that they also shared other traits of a K-selected reproductive strategy, such as maternal care and social behavior (O'Keefe and Chiappe, 2011). The injured animal may have been able to survive the attack, at least in the early stages of healing, through parental or social care or by moving to a safer feeding ground out of reach of predators, at least for part of the year (philopatric behavior) (Hueter et al., 2004). If healing was prolonged and the limb functionally immobile into adulthood, it may be speculated to have survived by retaining some of its juvenile characteristics (smaller body size and retention of the shape of the healthy glenoid fossa) inducing an epimeletic behavior in members of its social group (de Almeida Prado, 2000; Huang, 2006; Warren-Smith and Dunn, 2006).

\section{ACKNOWLEDGEMENTS}

The authors would like to thank Drs. R. Araújo and K. Claeson for their most helpful comments.

\section{REFERENCES}

Andrews, C.W. 1895. On the development of the shoulder-girdle of a Plesiosaur (Cryptoclidus oxoniensis, Phillips, sp.) from the Oxford Clay. Annals and Magazine of Natural History, 15:333-346.

Andrews, C.W. 1913. A Descriptive Catalogue of the Marine Reptiles of the Oxford Clay. Vol. 2. British Museum (Natural History), London.

Araújo, R. and Correia, F. 2015. Soft-tissue anatomy of the Plesiosaur pectoral girdle inferred from basal Eosauropterygia taxa and the extant phylogenetic bracket. Palaeontologia Electronica 18.1.8A:32p, https://doi.org/10.26879/446 http://palaeo-electronica.org/content/2015/1062-plesiosaur-pectoral-myology

Araújo, R. and Polcyn, M.J. 2013. A biomechanical analysis of the skull and adductor chamber muscles in the Late Cretaceous Plesiosaur Libonectes. Palaeontologia Electronica 16.2.10A:25p. https://doi.org/10.26879/287 http://palaeo-electronica.org/content/2013/418-plesiosaur-mastication

Araújo, R., Polcyn, M.J., Lindgren, J., Jacobs, L.L., Schulp, A.S., Mateus, O., Olímpio Gonçalves, A., and Morais, M.-L. 2015a. New aristonectine elasmosaurid plesiosaur specimens from the Early Maastrichtian of Angola and comments on paedomorphism in plesiosaurs. Netherlands Journal of Geosciences, 94:93-108

Araújo, R., Polcyn, M.J., Schulp, A.S., Mateus, O., Jacobs, L.L., Olímpio Gonçalves, A., and Morais M.-L. 2015b. A new elasmosaurid from the early Maastrichtian of Angola and the implications of girdle morphology on swimming style in plesiosaurs. Netherlands Journal of Geosciences, 94:109-120.

Bailleul, A.M., Scannella, J.B., Horner, J.R., and Evans, D.C. 2016. Fusion patterns in the skulls of modern archosaurs reveal that sutures are ambiguous maturity indicators for the Dinosauria. PLoS ONE, 11:e0147687.822 https://doi.org/10.1371/journal.pone.0147687.

Brown, D.S. 1981. The English Upper Jurassic Plesiosauroidea (Reptilia) and a review of the phylogeny and classification of the Plesiosauria. Bulletin of the British Museum of Natural History (Geology), 35:253-347.

Carpenter, K., Sanders, F., Reed, B., Reed, J., and Larson, P. 2010. Plesiosaur swimming as interpreted from skeletal analysis and experimental results. Transactions of the Kansas Academy of Science, 113:1-34. 
Chattergee, S. and Small, B.J. 1989. New plesiosaurs from the Upper Cretaceous of Antarctica. In Crame, J.A. (ed.), Origins and Evolution of the Antarctic Biota. Geological Society Special Publication, 47:197-215.

Clark, B.D. and Bemis, W. 1979. Kinematics of swimming of penguins at the Detroit Zoo. Journal of Zoology, 188:411-428.

Conybeare, W.D. 1824. On the discovery of an almost perfect skeleton of the Plesiosaurus. Transactions of the Geological Society London, 1:381-389.

de Almeida Prado, C.P., Uetanabaro, M., and Lopes, F. 2000. Reproductive strategies of Leptodactylus chaquensis and L. podicipinus in the Pantanal, Brazil. Journal of Herpetology, 34:135-139. https://doi.org/10.2307/1565249

De Boer, H.H., van der Merwe, A.E., Hammer, S., Steyn, M,. and Maat, G.J. 2015. Assessing post-traumatic time interval in human dry bone. International Journal of Osteoarchaeology, 25:98-109.

DePalma, R.A. II, Burnham, D.A., Martin, L.D., Rothschild, B.M., and Larson, P.L. 2013. Physical evidence of predatory behavior in Tyrannosaurus rex. Proceedings of the National Academy of Sciences, 110:12560-12564.

Douglas, M.J. 1965. Notes on the red fox (Vulpes vulpes) near Braemar, Scotland. Journal of Zoology, 147:228-233.

Einarsson, E., Lindgren, J., Kear, B.P., and Siverson, M. 2010. Mosasaur bite marks on a plesiosaur propodial from the Campanian (Late Cretaceous) of southern Sweden. GFF, 132:123-128.

English, A.W. 1976. Limb movements and locomotor function in the California sea lion (Zalophus californianus). Journal of Zoology, 178:341-364.

Gaillard, C., Bernier, P., Barale, G., Bourseau, J.-P., Buffetaut, E., Ezquerra, R., Gall, J.-C., de Lapparent de Broin, F., Renous, S., and Wenz, S. 2003. A giant Upper Jurassic turtle revealed by its trackways. Lethaia, 36:315-322.

Godfrey, S.J. 1984. Plesiosaur subaqueous locomotion: a reappraisal. Neues Jahrbuch für Geologie und Paläontologie. Monatshefte, 42:661-672.

Halstead, L.B. 1969. The Pattern of Vertebrate Evolution. Oliver and Boyd, Edinburgh.

Halstead, L.B. 1989. Plesiosaur locomotion. Journal of the Geological Society, London, 146:3740.

Hammer, Ø., Harper, D.A.T., and Ryan, P.D. 2001. PAST: Palaeontological Statistics software package for education and data analysis. Palaeontologia Electronica 4.1.4A:9p, http://palaeo-electronica.org/2001_1/past/past.pdf

Hershkovitz, I.H., Latimer, B., Dutour, O., Jellema, L., Wish-Baratz, S., Rothschild, C., and Rothschild, B.M. 1997. Why do we fail in aging the skull from sagittal sutures? American Journal of Physical Anthropology, 103:393-399.

Hone, D.W. and Watabe, M. 2010. New information on scavenging and selective feeding behavior of tyrannosaurids. Acta Palaeontologica Polonica, 55:627-634.

Huang, W.-S. 2006. Parental care in the long-tailed skink, Mabuya longicaudata on a tropical Asian island. Animal Behaviour, 72:791-795. https://doi.org/10.1016/j.anbehav.2005.12.011

Hudson, J.D. and Martill, D.M. 1994. The Peterborough Member (Callovian, Middle Jurassic) of the Oxford Clay Formation at Peterborough, UK. Journal of the Geological Society, 151:113124. https://doi.org/10.1144/gsjgs.151.1.0113

Hueter, R.E., Heupel, M.R., Heist, E.J., and Keeney, D.B. 2004. Evidence of philopatry in sharks and implications for the management of shark fisheries. Journal of Northwest Atlantic Fishery Science, 35:239-247. https://doi.org/10.2960/J.v35.m493

Karl, H.V. 2012. Bite traces in a turtle shell fragment from the Kimmeridgian (Upper Jurassic) of Northern Germany. Studia Palaeocheloniologica, 4:25-30.

Lingham-Soliar, T. 2000. Plesiosaur locomotion: Is the four-wing problem real or merely an atheroretical exercise? Neues Jahrbuch für Geologie und Paläontologie, Abhandlungen, 217(1):45-87.

Liu, S., Smith, A.S., Gu, Y., Tan, J., Liu, K., and Turk, G. 2015. Computer simulations imply forelimb-dominated underwater flight in plesiosaurs. PLoS Computational Biology, 11(12):e1004605. https://doi.org/10.1371/journal.pcbi.1004605

Long, J.H., Jr, Schumacher, J., Livingston, N., and Kemp, M. 2006. Four flippers or two: tetrapodal swimming with an aquatic robot. Bioinspiration and Biomimetics, 1:20-29.

Maisch, M.W. and Rücklin, M. 2000. Cranial osteology of the sauropterygian Plesiosaurus brachypterygius from the Lower Toarcian of Germany. Palaeontology, 43:29-40. 
Martill, D.M., Taylor, M.A., Duff, K.L., Riding, J.B., and Bown, P.R. 1994. The trophic structure of the biota of the Peterborough Member, Oxford Clay Formation (Jurassic), UK. Journal of the Geological Society, London, 151:173-194.

Massare, J.A. 1988. Swimming capabilities of Mesozoic marine reptiles: implications for method of predation. Paleobiology, 14:187-205.

McTaggart Cowan, I. 1946. Parasites, diseases, injuries, and anomalies of the Columbian blacktailed deer, Odocoileus hemionus columbianus (Richardson), in British Columbia. Canadian Journal of Research, 24(2):71-103.

O'Keefe F.R. and Chiappe L.M. 2011. Viviparity and K-selected life history in a Mesozoic marine plesiosaur (Reptilia, Sauropterygia). Science, 333:870-873.

Riess, J. and Frey, E. 1991. The evolution of underwater flight and the locomotion of plesiosaurs, p. 131-144. In Rayner, J. M.V. and Wooton, R.J. (eds.), Biomechanics in Evolution. Cambridge University Press, Cambridge, UK.

Robinson, J.A. 1975. The locomotion of plesiosaurs. Neues Jahrbuch für Geologie und Paläontologie, Abhandlungen, 149:286-332.

Rothschild, B.M. and Martin, L.D. 2006. Skeletal Impact of Disease. Museum of Natural History Press, Albuquerque, New Mexico.

Rothschild, B.M., Schultze, H.-P., and Pellegrini, R. 2012. Herpetological Osteopathology: Annotated Bibliography of Amphibians and Reptiles. Springer, New York.

Rowley-Conwy, P. 1990. On the osteological evidence for Palaeolithic domestication: barking up the wrong tree. Current Anthropology, 31:543-547.

Smith, A.S. 2013. Morphology of the caudal vertebrae in Rhomaleosaurus zetlandicus and review of the evidence for a tail fin in Plesiosauria. Paludicola, 9(3):144-158.

Smellie, W.R. 1916. A new Oxfordian plesiosaur in the Hunterian Museum, Glasgow University. Transactions of the Royal Society of Edinburgh, 51:609-629.

Stern, W.G. 1936. Acute transverse bone atrophy. Journal of Bone and Joint Surgery American, 18:659-666.

Tarlo, L.B. 1957. The scapula of Pliosaurus macromerus Phillips. Palaeontology, 1(3):193-199.

Tully, T.N. Jr. 2002. Basic avian bone growth and healing. Veterinary Clinics of North America: Exotic Animal Practice, 5:23-30.

Walker, W.F. Jr. 1971. Swimming in sea turtles of the family Cheloniidae. Copea, 2:229-233.

Warren-Smith, A.B. and Dunn, W.L. 2006. Epimeletic behaviour toward a seriously injured juvenile bottlenose dolphin (Tursiops sp.) in Port Phillip, Victoria, Australia. Aquatic Mammals, 32:357-362.

Zhang, Q., Wen, W., Hu, S., Benton, M.J., Zhou, C., Xie, T., Lü, T., Huang, J., Choo, B., Chen, Z.-Q., Liu, J., and Zhang, Q. 2014. Nothosaur foraging tracks from the Middle Triassic of southwestern China. Nature Communications, 5:3973. https://doi.org/10.1038/ncomms4973 